\title{
ENSINO E APRENDIZAGEM POR MEIO DA MODELAGEM MATEMÁTICA NO NOVO ENSINO MÉDIO
}

\author{
Leonam Vieira Hemann ${ }^{1}$; Karla Jaqueline Souza Tatsch²
}

\section{RESUMO}

Este trabalho apresenta resultados parciais de um estudo de caso que busca reconhecer como a Modelagem Matemática pode contribuir para a aprendizagem de noções básicas de estatística e de funções polinomiais de $1^{\circ}$ grau por alunos de uma turma de $2^{\circ}$ ano do ensino médio. Para o estudo, o autor elaborou uma sequência de atividades de ensino que será aplicada em aulas do componente curricular Projetos Matemáticos e Sustentabilidade que integra um dos itinerários formativos na estrutura do novo ensino médio. A investigação tem uma abordagem qualitativa onde a observação participante e os materiais produzidos pelos alunos serão os instrumentos de coleta de dados. A partir dos estudos por meio das revisões de literatura $e$ no planejamento das atividades, 0 autor reconhece algumas potencialidades que a estratégia apresenta para contribuir na construção da aprendizagem por alunos nos diferentes níveis de ensino.

Palavras-chave: Formação de Professores; Recursos Tecnológicos Digitais no Ensino; Sustentabilidade.

Eixo Temático: Educação, Cultura e Comunicação (ECC)

\section{INTRODUÇÃO}

Neste artigo, apresenta-se parte de uma proposta de intervenção didática com atividades de ensino e aprendizagem de Matemática para o Ensino Médio envolvendo o estudo de noções de estatística e funções polinomiais de $1^{\circ}$ grau, com a utilização da Modelagem Matemática como possibilidade para a construção da aprendizagem pelos alunos.

Realizado durante a disciplina de Trabalho Final de Graduação I do curso de Matemática Licenciatura, na Universidade Franciscana e aplicado na disciplina de

\footnotetext{
1 Universidade Franciscana - UFN - Ihemann@ufn.edu.br

2 Universidade Franciscana - UFN - karlasouzat@prof.ufn.edu.br
} 
Trabalho Final de Graduação II, o presente trabalho apresenta uma sequência de atividades de ensino abordando a temática com referência no cotidiano dos alunos e com a utilização de tecnologias digitais.

Tais atividades foram aplicadas junto a uma turma de alunos do $2^{\circ}$ ano do Ensino Médio de uma escola pública localizada na região central do Rio Grande do Sul e propõem a análise, pelos alunos, de tarifas de energia elétrica explorando objetos de conhecimento.

Entende-se que o ensino de Matemática precisa explorar estratégias que levem o aluno a desenvolver e aprimorar habilidades e competências de um ser autônomo, responsável e crítico. O uso da Modelagem Matemática apresenta-se com potencialidades para isso.

Além disso, é uma estratégia que, por tratar de assuntos reais em sala de aula, requer, por vezes, o uso de tecnologias digitais pelo aluno já que os objetos matemáticos precisam ser tratados com seleção, organização e análise das variáveis envolvidas.

Diferentes são as situações cotidianas em que conhecimentos relativos a funções polinomiais de primeiro grau é evidenciado, no entendimento, por exemplo, sobre cobranças por serviços prestados, como na tarifa de energia elétrica. Essa abordagem, que se constitui um dos clássicos exemplos de aplicação de conhecimentos matemáticos, foi a temática escolhida para a elaboração das atividades de ensino a partir da necessidade de abordar questões voltadas à Sustentabilidade ambiental.

Para o estudo que aqui se apresenta buscou-se reconhecer como a Modelagem Matemática pode contribuir para a aprendizagem de noções básicas de estatística e de funções polinomiais de $1^{\circ}$ grau por alunos de uma turma de $2^{\circ}$ ano do ensino médio.

A sequência de atividades foi elaborada para ser implementada por meio da inserção do autor em aulas no formato de ensino remoto, de uma turma em que atua como bolsista residente, e está previsto o uso dos aplicativos Google Sala de Aula e Meet, que os alunos utilizam desde o mês de junho de 2020, disponibilizados aos 
alunos das escolas da rede estadual do estado do Rio Grande do Sul (Rio Grande do Sul, 2020).

O Ensino Remoto é uma metodologia adotada diante de um momento de urgência, onde as aulas podem ser ao vivo ou gravadas, com a interação do professor regente da disciplina com os alunos. Os materiais, nessa sistemática, são personalizados e criados na busca por atender o desenvolvimento de habilidades e competências mesmo sem contar com a presencialidade (UBM, 2020).

\section{METODOLOGIA}

Trata-se de um estudo de caso, precedido de um estudo bibliográfico, com a previsão de aplicação da sequência de atividades de ensino numa turma de alunos, no formato remoto. O estudo de caso, segundo Pereira (2018), é uma descrição e análise, mais detalhada possível, apresentando uma particularidade, assim tornando um estudo rico em dados e informação, de modo a contribuir com a área de conhecimento em que for utilizada.

Para Yin (2001), o estudo de caso apresenta a capacidade de lidar com uma ampla variedade de evidências, além de que pode estar disponível no estudo histórico convencional.

A pesquisa contará com uma abordagem qualitativa e a coleta de dados se dará por meio da observação participante, os materiais construídos pelos alunos e a gravação das aulas, de forma a perceber as contribuições da Modelagem Matemática para a construção da aprendizagem pelos estudantes observados.

Para Gerhardt (2009), a abordagem qualitativa é aquela que não se detém somente a buscar dados numéricos ou estatísticos sobre o tema. Neste estudo o interesse se apresenta no processo educativo, essencialmente na busca pelas potencialidades da Modelagem para a construção da aprendizagem de determinados objetos matemáticos.

A observação participante é aquela que o pesquisador está diretamente ligado com os sujeitos de pesquisa, conseguindo observar as reações de forma direta no desenvolvimento no processo. Para Mazucato (2018), ela apresenta duas tipologias, a natural e a artificial; na primeira, o observador pertence à comunidade 
que investiga, assim, um exercício constante de afastamento e de exterioridade no processo de construção de dados, e na segunda modalidade nota-se que o sujeito do conhecimento é externo ao grupo estudado e se integra com finalidade de obter as informações. Para este trabalho, será a observação natural, pois o autor está inserido nesse componente como residente pedagógico, num trabalho junto ao Programa Residência Pedagógica - RP.

Segundo Lüdke e André (1986), por meio da observação participante é possível uma experiência direta que apresenta o melhor teste de verificação da ocorrência de um determinado fenômeno.

Os sujeitos de pesquisa serão alunos de uma turma de $2^{\circ}$ ano do ensino médio, do componente Projetos Matemáticos e Sustentabilidade que integra um dos itinerários formativos no formato do novo ensino médio.

\section{REFERENCIAL TEÓRICO}

A Modelagem Matemática é uma estratégia de ensino e aprendizagem em que o professor oferece ao aluno a possibilidade de explorar temas com referência no cotidiano, modelando o comportamento de determinados eventos e oportunizando a construção de conhecimentos ou retomar conceitos já abordados.

Bassanezi (2006) acredita que o gosto pelo estudo da Matemática se desenvolve de forma mais facilitada quando provocado por interesses e estímulos externos, referentes ao mundo real, entendendo que a aplicabilidade no ensino é o caminho para a conquista da qualidade. Para ele, a Modelagem Matemática promove uma mudança para o processo educativo, valorizando a interação do aluno com o ambiente natural.

Para Chaves e Bisognin (2006) a Modelagem Matemática é uma proposta para o ensino de Matemática que vai de acordo com questionamentos, tanto para professores quanto alunos: Como fazer com que a Matemática seja reconhecida como uma ciência necessária e útil no dia-a-dia das pessoas? E como proporcionar que os conhecimentos adquiridos não sejam armazenados de maneira passageira, mas que permaneçam por muito tempo, até mesmo para o resto da vida? 
Caldeira (2009) afirma que não se trata apenas de oportunizar ao aluno o aprender o que ele utilizará para seu cotidiano, mas selecionar e apresentar conteúdos matemáticos necessários para compreender acerca da realidade e fortalecer seus vínculos na sociedade.

Nesse contexto, os recursos tecnológicos digitais se apresentam como importantes recursos para a condução das próprias aulas e para a interpretação, a organização e a análise dos dados durante uma atividade de Modelagem Matemática.

Diferentes empresas fornecem acesso a aplicativos que permitem a abordagem de tecnologias digitais no ensino tais como a Google que apresenta uma plataforma com dois aplicativos, Google Sala de Aula e o Google Meet, que têm se mostrado de grande valia para a área da educação. O Sala de Aula oferece a possibilidade de criar um ambiente totalmente online, para professores tanto disponibilizarem seus materiais para uma turma, como realizarem atividades e também realizarem vídeo chamadas, e o Meet permite a interação simultânea, remota, entre professores e alunos.

O presente trabalho, apresenta a proposta de explorar esses dois aplicativos, por estarem disponibilizados aos alunos, sujeitos da pesquisa, onde o autor atua por meio do Programa Residência Pedagógica. Além deles, também explorará o uso do Google Planilhas, recurso que apresenta linhas e colunas, que representam células, onde todo o ambiente pode ser programado com comandos já existentes.

A utilização de tecnologias digitais no ensino é de fundamental importância para o desenvolvimento de atividades práticas com os alunos. Camillo (2017) afirma sobre o favorecimento dessa na qualidade do trabalho didático no tratamento de dados estáticos, da exploração geométricas e da manipulação de funções ao inserir a informática em sala de aula.

O conteúdo de funções, apresenta fatores tanto fixos quanto variáveis, quando comparado ao Planilhas, que apresenta células, em que é possível a inserção de variáveis, ambos podem ser trabalhados juntos.

A utilização desta ferramenta possibilita ao aluno aplicar conceitos já estudados anteriormente ou construir novos conhecimentos. Em Borba e Penteado 
(2019), é apresentada uma atividade envolvendo a Modelagem, com a utilização do recurso gráfico, apresentado potencialidades interessantes do recurso.

O trabalho pedagógico proposto viabilizará, além da construção de conhecimentos sobre noções básicas de estatística e sobre função polinomial de primeiro grau, a utilização da ferramenta gratuita do Google Planilhas, a partir de situações-problemas na análise e interpretação de tarifas de energia elétrica dos alunos.

\section{RESULTADOS E DISCUSSÕES}

Para a atividade em questão, será composta da seguinte forma: Introdução sobre Planilhas Eletrônicas, ensino de funções básicas nas Planilhas Eletrônicas, uma abordagem prática e por fim resolução de uma atividade em Planilhas Eletrônicas.

Uma forma de apresentar um ensino que motive o aluno para aprender é por meio da discussão, em aulas de Matemática, sobre temas com relação ao contexto real. Os conhecimentos matemáticos estão estreitamente relacionados a muitos fatores presentes no cotidiano e o professor pode explorá-los em sala de aula.

Para a realização do presente trabalho, como proposta de atividades de ensino com a Modelagem Matemática, foi utilizada a temática da análise e interpretação de tarifas de energia elétrica.

Sobre a introdução do recurso planilhas, é proposta a apresentação, ao aluno, do ambiente inicial, conforme Figura 1.

Figura 1 - Tela do Google Planilhas

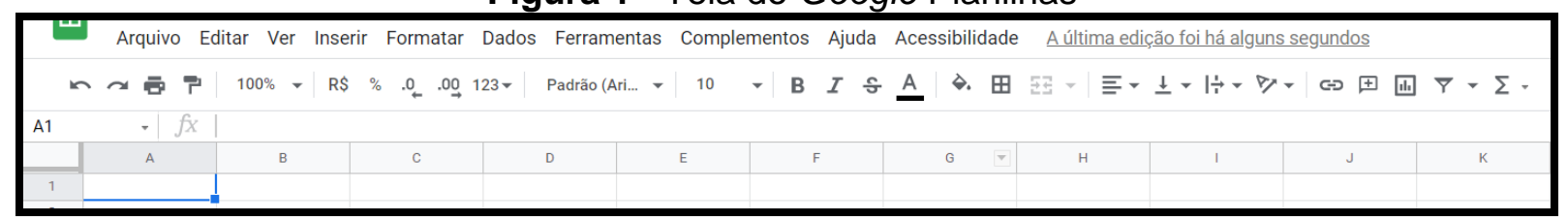

Fonte: Autor

A inserção de dados, deve ser realizada em cada célula, para então ser realizados os cálculos de adição, subtração, multiplicação, divisão, potenciação e, por fim, radiciação. 
A partir disso, propõe-se a apresentação de diferentes funcionalidades do Google Planilhas, conforme exemplifica a imagem que se apresenta na Figura 2, a seguir.

Figura 2 - Operações no aplicativo Google Planilhas.

\begin{tabular}{|r||r|r|r|}
\hline & A & B & \multicolumn{1}{|c|}{ C } \\
\hline 1 & & & D \\
\hline 2 & Número 1 & 3 Soma = B3+B2 & 7 \\
\hline 3 & Número 2 & 4 & -1 \\
\hline 4 & & Mulferença = B2-B3 & 12 \\
\hline 5 & & Divisão = B2/B3 & 0,75 \\
\hline 6 & & Exponenciação = B2^B3 & 81 \\
\hline 7 & & Raiz = SQRT(B3) & 2 \\
\hline
\end{tabular}

Fonte: O Autor.

Neste trabalho de ensino, serão exploradas tarifas de energia elétrica com a construção de modelos matemáticos.

Para as construções e análises dos modelos previstos serão consideradas a Tarifa de Energia - TE e Tarifa de Uso do Sistema de Distribuição - TUSD, onde TE significa o valor a ser pago pela energia que o local consome mensalmente e TUSD traduz o valor das despesas da concessionária para "levar" a energia da fonte até o consumidor final (TAB ENERGIA, 2021).

Para as situações propostas aos alunos, serão selecionadas algumas variáveis, para que objetivos de ensino e aprendizagem sejam oportunizados de ser alcançados.

Como atividades inicias a serem propostas aos alunos tem-se:

1) Calcular o valor a ser pago, no mês de Abril, com bandeira vermelha no valor de $R \$ 4,16$, tendo a potência consumida de $150 \mathrm{kWh}$. Tarifa $R \$$ 0,91573605 .

2) Calcular o valor a ser pago, no mês de Maio, com bandeira amarela, tendo a potência consumida de $200 \mathrm{kWh}$. Tarifa $\mathrm{R} \$ 0,9005$.

3) Calcular o valor a ser pago, no mês de Março, com bandeira Amarela, tendo a potência consumida de $100 \mathrm{kWh}$. Tarifa $\mathrm{R} \$ 0,9198$.

Tem-se uma suposta resolução, pelo aluno, para essas atividades, na Figura 3 , a seguir. 
Figura 3 - Desenvolvimento de um Determina Aluno.

\begin{tabular}{|c|c|c|c|c|c|c|c|c|c|}
\hline \multicolumn{10}{|c|}{ Calcular o valor a ser pago, no mês de Abril, com bandeira vermelha no valor de RS 4,16, tendo a potência consumida de $150 \mathrm{kWh}$. } \\
\hline$f(x)=a^{*} x+b$ & & & $\mathrm{a}$ & $\mathrm{x}$ & $\mathrm{b}$ & Resultado & & & \\
\hline \multicolumn{3}{|c|}{$f($ consumo $)=$ tarifa ${ }^{*}$ consumo + bandeira } & 0,91573605 & 150 & 4,16 & 141,5204075 & & & \\
\hline & & & & & & & & & \\
\hline \multicolumn{10}{|c|}{ Calcular o valor a ser pago, no mês de Maio, com bandeira amarela, tendo a potência consumida de $200 \mathrm{kWh}$. } \\
\hline tarifa & 0,9005 & & $f(x)=a^{*} x+b$ & & & & & & \\
\hline consumo & 200 & & \multicolumn{3}{|c|}{$f($ consumo $)=$ tarifa * consumo + bandeira } & a & $\mathrm{x}$ & $\mathrm{b}$ & Resultado \\
\hline bandeira & 1,5 & & $f(200)=0,9005^{\prime} ;$ & & & 0,9005 & 200 & 1,5 & 181,6 \\
\hline \multicolumn{10}{|c|}{ Calcular o valor a ser pago, no mês de Março, com bandeira Amarela, tendo a potência consumida de $100 \mathrm{kWh}$. } \\
\hline & & & & & & & & & \\
\hline tarifa & 0,9198 & a & $\mathrm{x}$ & $\mathrm{b}$ & Resultado & & & & \\
\hline consumo & 100 & 0,9198 & 100 & 1,5 & 93,48 & & & & \\
\hline bandeira & 1,5 & & & & & & & & \\
\hline
\end{tabular}

\section{CONCLUSÃO}

Das atividades apresentadas, concluímos que a Modelagem Matemática é uma estratégia que se apresenta com potencial para que o aluno seja ativo na construção da aprendizagem ao mesmo tempo em que se constitui como ser autônomo e crítico.

A experiência da Residência na modalidade de ensino remoto, tem constatado a possibilidade de construção de aprendizagem dos alunos uma vez que se tem a interação com o professor e o processo de aprendizagem, visto que, segue um planejamento de ensino e de aprendizagem.

Também, tal trabalho, apresentou uma participação interessada e responsável por parte dos alunos, foi percebido isso, durante a realização das atividades e as aulas, onde eles interagiam tanto em questionamento nas aulas quanto a responsabilidade de enviar as tarefas solicitadas.

Dos recursos tecnológicos digitais com a Modelagem Matemática, foi possível perceber durante as aulas, que isso auxilia, na construção de pensamento, onde é possível mostrar e demonstrar aos alunos no decorrer da explicação as possíveis soluções.

\section{REFERÊNCIAS}

BASSANEZI, Rodney Carlos. Ensino-aprendizagem com Modelagem Matemática: uma nova estratégia. São Paulo: Editora Contexto, 2006. 
BORBA, M. C.; PENTEADO, M. G. Informática e Educação Matemática. 6. ed. Belo Horizonte: Autêntica, 2019.

CALDEIRA, Ademir Donizeti. Modelagem Matemática: um outro olhar.

ALEXANDRIA: Revista de Educação em Ciência e Tecnologia. Florianópolis, v.2, n.2, p.33-54, jul. 2009.

CAMILLO, Cíntia M.; O Uso do Software Excel no Ensino da Matemática, 2017. Disponível em: <https://revistaacessolivre.files.wordpress.com/2017/06/013_excelno-ensino-da-matemc3a1tica.pdf>. Acesso em: 9 jun. 2021.

CHAVES, Cristina Medianeira de Souza. BISOGNIN, Eleni. A Modelagem Matemática na Sala de Aula: uma forma de diversificar o ensino. In: IX Encontro Gaúcho de Educação Matemática, 2006, Caxias do Sul. Anais. IX EGEM, 2006.

GERHARDT, Tatiana E. e SILVEIRA, Denise T. Métodos de Pesquisa. 1a ed. Porto Alegre: Editora da UFRGS, 2009.

LÜDKE, Menga; ANDRÉ, Marli E.D.A. Métodos de coleta de dados: observação, entrevista e análise documental. In: Pesquisa em educação: abordagens qualitativas, p. 25-44, São Paulo: EPU, 1986. Disponível em: $<$ https://edisciplinas.usp.br/pluginfile.php/4091392/mod_resource/content/1/Lud_And cap3.pd>. Acesso em 14 abr. 2021.

MAZUCATO, Thiago; ZAMBELLO, Aline V.; SOARES, Alessandra G.; TAUIL, Carlos E.; DONZELLI, Cledivaldo A.; FONTANA, Felipe; CHOTOLLI, Wesley P.

Metodologia da Pesquisa e do Trabalho Científico. Penápolis: FUNEPE, 2018. Disponível em: <www.funepe.edu.br>. Acesso em 12 abr. 2021.

PEREIRA, Adriana S.; SHITSUKA, Dorlivete M.; PARREIRA, Fabio J.; SHITSUKA, Ricardo. Metodologia da Pesquisa Científica. Santa Maria: NTE, 2018.

RIO GRANDE DO SUL. Estabelecido plano de ações para as escolas estaduais durante o período de suspensão das aulas - Secretaria da Educação. Secretaria da Educação. Porto Alegre: SEDUC/RS, 2020. Disponível em:

$<$ https://educacao.rs.gov.br/seduc-estabelece-plano-de-acoes-para-as-escolasestaduais-durante-o-periodo-de-suspensao-das-aulas>. Acesso em: 1 jul. 2021.

SILVA, Jane; TE e TUSD: entenda as taxas da conta de luz da sua empresa | TAB energia. Disponível em: <https://tabenergia.com.br/blog/te-e-tusd/>. Acesso em: 9 jun. 2021.

UBM. Entenda as diferenças entre aula remota e EAD. Conhecimento Transforma. G1. Brasília: G1, 2020. Disponível em: <https://g1.globo.com/rj/sul-do-rio-costaverde/especial-publicitario/ubm/conhecimentotransforma/noticia/2020/08/10/entenda-as-diferencas-entre-aula-remota-eead.ghtml>. Acesso em: 5 jul 2021. 


\section{PUFN}

YIN, R. K. Estudo de Caso: Planejamento e Métodos. 2. ed. Porto Alegre:

Bookman, 2001. Disponível

em:<https://saudeglobaldotorg1.files.wordpress.com/2014/02/yin-

metodologia_da_pesquisa_estudo_de_caso_yin.pdf >. Acesso em: 14 abr. 2021. 